\title{
Haphazard Archive: The Epistemological, Aesthetic, and Political Contradictions of US Television
}

\section{Lynne Joyrich}

A recent article reporting on an archive of American broadcasting describes a "Special Collections in Mass Media and Culture" as "reflect[ing a] bygone era"-an era "when people arranged their lives according to television's set schedule." 1 It is common to discuss archives-and, in fact, television programs -in such terms: as simply reflections of their time periods and as "set," stabilized not only literally by the solidity of the console (the TV set itself) but by the conventions of the TV industry and even by the protocols of television studies. Yet television is not quite so simple as such comments on TV's "bygone era" suggestand not only because we are now in a digitally convergent age of multiple screens, accessible across a variety of times and places. Rather, as I hope to show, the multiplicities and instabilities of US television emerge from the very formations of televisual textuality, television archiving, and television studies, and from the work that those formations do (that is, their productivity —not just via their financial circulations but across cultural, knowledge, and affective circulations as well). To demonstrate this, in this essay I would like to reflect on my own work as a television studies scholar, a television studies teacher, and an informal television archivist (with a personal collection of hundreds of things I've recorded from television), with the aim of using these reflections to comment on the contradictions of the epistemologies, the aesthetics, and the politics of US television and television studies.

When I began working in television studies (specifically, feminist television studies) in the bygone days of the early 1980s, there were very few official television archives, nor were there even many commercial outlets for purchasing programs. Television scholars of the time relied on their own resources (personal VCRs and recording trading among one another) to amass research and teaching 
material. In my case, this led to a personal archive-one I still use and have passed on to my own students, many of whom are now TV studies teachers themselves - with an enormous amount of material that ranges from random episodes of US soap operas, game shows, talk shows, and tele-evangelical broadcasts to complete sets of various series, some long-lasting and now recognized as "part of our television heritage" and some one-season programs, barely remembered today. My archive also includes major live news eruptions as well as more mundane news updates, local public access offerings, and even such "trivial" things as infomercials and weather reports. It incorporates, in other words, texts that would likely be considered quotidian and insignificant, along with texts that have gone on to become celebrated (as significant "quality television," "cult TV," and notable historical "TV events").

The haphazard nature of such personal TV collecting might seem at odds with the need for rigor in TV analysis and teaching-yet I want to argue that this tension between the random and the rigorous actually reveals the paradoxes of TV studies and of TV itself, as such archival amassing, in its individual contours, both illuminates and interrupts the very notion of TV as a "mass" medium. It shows, in other words, how television, in its variety as a collection of texts, speaks to a "general public" even as it does so for each specific viewer in quite particular ways. It likewise both furthers and fractures the notion of a TV studies canon, as this archive is a production yet fragmentation, across public and private screenings, of both new and old texts, marking what's passed down even as it also calls to mind what's passed over. It is therefore particularly appropriate for TV, given television's own unifications and multiplicities, public and private existences, continuous and changing formations. For, however much we may take it for granted, US television exhibits a curious logic: one that exists on the border between past, present, and future (as networks proclaim their up-to-dateness while also airing reruns and announcing what will soon be coming up); between the domestic and social (as the outside world enters our inner spaces, and we are invited to witness the private escapades of public figures); and between sameness and difference (as continuity is created by the sequencing of discontinuous segments, and discontinuity emerges even as, or because, TV texts must attempt to sustain themselves over long periods of time). ${ }^{2}$ This (il)logic then necessarily both constitutes and complicates any television collection. Thus, 
while handing down such individual archives in part yields a settled TV tradition, it also, in other ways, unsettles TV studies-and in ways, I want to suggest, that reveal the complexity of television itself.

Still, though I may be tempted to brag about my video collection, today there seems to be no obvious need for such amassed personal archives, as it is so much easier to find television material. Indeed, there is a sense that, in this day and age, everything is available: now you can easily buy packaged DVD sets of seasons' worth of TV series; access programs via streaming services like Netflix, Hulu, and Amazon Instant Video; or even just get shows by illegal downloading-making, it seems, all of TV accessible. But, of course, we need to question that "all." What does it include, and what does it omit? Isn't this claim to have "everything" already replicating the rhetoric of commercial TV and consumer culture itself: the claim to provide all, when really what are provided are the things that the market itself deems sellable? And at the same time, doesn't this actually mask TV's logics, allowing for a kind of disavowal of the televisual in its most banal, but also perhaps most characteristic, forms? For, of course, what is left out of the everything that is promised by new delivery systems of old television are a great many things in which, presumably, no one is interested: the "detritus" of everyday TV, like those minor news breaks, weather reports, not particularly exciting episodes of talk and game shows, midweek soap opera episodes, reruns of never particularly popular programming, religious program bits, infomercials, and so on-including, significantly, TV commercials, which are rarely included in boxed DVD sets, preventing us from seeing how the flow of that programming was actually originally constructed. It is for this reason, or what we might call this available evasion, that many of my students can claim, at one and the same timeand with no apparent sense of irony-that they "never watch television" and that they have seen "everything" on TV. ${ }^{3}$

My own haphazard, if extensive, taping captured some of these things that today would be left out, while also always revealing the limits of that capture. Even the sheer physicality of video tapes (with their imposed time caps on recording as well as the spatial caps that necessarily arise in trying to amass and make room for video cassettes) made it clear that one couldn't get everything—reminding us, by this very materiality, that TV is always defined by the "more coming up"). As that reminder of televisual excess indicates, such personal archival practices could also expose certain 
practices of viewing and textuality-and, in so doing, they might be seen as less random than revelatory. Obviously, what I taped and traded (along with what everyone else taped and traded) was determined by particular interests (both personal and pedagogical) as well as by availability (of tapes, time, storage space); so, rather than being complete, my archive is segmented and skewed, partial and particular. But that itself indicates something about the partialities, the segmentations and flows, of television itself. And sometimes, even if in idiosyncratic ways, what I (or others) taped (or didn't tape) could reveal deeper logics (or illogics) of TV and TV viewing.

Let me offer two anecdotes to illustrate this point. My first story is about a media studies friend who was working on soap opera's treatment of romance, weddings, and marriage-yet who never seemed able to capture a soap wedding despite our repeated good tries (because, after she'd miss getting one on tape, she'd often contact me, living in a later time zone; but she wouldn't get me in time, or my efforts too would fail, or l'd succeed but the tape would get lost or damaged in the mail, and so on). This situationliteralizing the intensity yet fragility of soap opera connections, both on and surrounding TV—proved (even if inadvertently) instructive. It pointed to and provoked reflections about soaps' own ambivalent production of matrimonial ceremonies (as rareish-while-still-regular high points but also points of crisis, always falling apart whenever one thinks that they're set) as well indicating viewers' ambivalent—and clearly symptomatic_relationships to these moments. These are moments that can simultaneously solidify and also shift not only diegetic soap communities but viewing communities variously invested in, or hostile to, certain relationalities on soaps. In other words, the complications we encountered in trying to access soap weddings existed in intriguing counterpoint to the centrality yet difficulties of heterosexual romance and marriage on the soaps themselves and the ways in which affect around these could be acted out-so, while our series of failed tapings was frustrating, it was also illuminating for thinking about TV serials.

Video Clip 1a

$\underline{\text { Video Clip 1b }}$ 


\section{Video Clip 1c}

In these excerpts from a Valentine's Day episode of One Life to Live (ABC, February 14, 2001), a lonely soap opera villainess character starts to watch TV-and winds up seeing her own life as a soap opera (with the bits that she sees on her television set incorporating clips from previous episodes of One Life to Live, familiar to regular viewers of the program). Through the connections and contrasts between the soap-within-a-soap and One Life to Live itself (for instance, the distinction between the fantasmatic diegetic soap that reaches "the end" and the framing text that continues on), viewers are encouraged to notice soap opera plotting (particularly regarding romance, marriage, family ties, and so on) and the constructions of gender and sexuality with which they are linked. Included, too, are some moments of direct address to the viewer via the $A B C$ promotions that "interrupt" (yet, of course, define) the soap opera.

My second story is about a more successful capture: my attempt to get the start of the Second Gulf War's "shock and awe" campaign (a.k.a. Operation Iraqi Freedom), which began during the night of March 19, 2003. In the days leading up to this, and earlier that day itself, there was talk about increasing tensions, and it was clear that something was going to happen very soon-but, the news anchors said, no one knew exactly when. Yet, unlike those news reporters and political commentators, I tried to figure this out (so l'd have it on tape) by calculating not in terms of political strategy per se, but in terms of the TV schedule and the logic of advertising. Specifically, I figured that, given George W. Bush's PR campaigns, he wouldn't want to interrupt a patriotic program like American Idol, but likely would want to insert himself into the time slot usually held by The West Wing (thus reasserting himself as the "real president" in place of the liberal faux president on that show). So that gave me my guess for day and rough time. I thought that they wouldn't want to be too obvious about this, so wouldn't begin right at the start of that time block but, say, ten to fifteen minutes in...so I set my VCR for 9:10, and I managed to catch the first air attacks almost precisely on time. (I think that the networks cut in with their "we interrupt this broadcast" announcement only two minutes after my taping started!) 
This clip from news coverage of the start of the Iraq War (ABC, March 19, 2003) includes President George W. Bush's announcement to the nation as well as anchor Peter Jennings and reporter Ted Koppel's discussion of the "surprising" timing of the start of the invasion.

Now, of course, maybe this was just a fluke, a lucky guess not tied to anything but coincidence. But even if that is the case, it indicates something about the way that we imagine TV's production of the national and international, the patriotic and the irreverent, the domesticated temporal and the geopoliticized spatial-not to mention its production of plotting and conspiracy theorizing, in which, as suggested in this example, we are instructed by TV itself. These two stories (of managing or not managing to get something via idiosyncratic VCR use) are themselves instructive, demonstrating how such taping and personal archiving could open up, if not always access to programming, then at least issues for thinking about TV programming and thus how this could be productive for TV studies.

Of course, today's modes of accessing television texts via DVDs or the internet also produce particular kinds of theorizing (with, I'm suggesting, various modes of access helping to encourage various corresponding modes of engagement and thinking). But, even as I'm delighted that it's now easier to get one's hands on TV texts for teaching and research, the kinds of knowledge formations that our current acquisition and archive formations yield are ones that I think are important to interrogate. As I elaborate in more detail elsewhere, current TV studies seem to me to be moving in two quite opposite (if simultaneous) directions, both of which, I believe, have risks (not only, as more typically assessed, rewards), and both of which I see as linked to today's ways of approaching television. ${ }^{4}$

On the one hand, many studies today emphasize moving "outside" of the box (going "beyond TV") to consider how television operates as part of convergence culture (an emphasis encouraged, obviously, by getting TV on the internet). ${ }^{5}$ On the other hand, other studies are moving more and more "inside" TV to focus closely on televisual aesthetics-an emphasis that I don't see as unrelated to the cultural authorization provided by things like packaged DVD sets of certain legitimated television programs (further legitimated by the erasure of the original, crass, "interrupting" commercials and, instead, accompanied by authorial commentary). ${ }^{6}$ These approaches are also not 
unrelated to one another, given a shared discourse of novelty (one shared with TV's promotional discourses as well). That is, whether moving from in to out or from out to in, both wind up with an image of a (supposedly) newly intricate medium; while many studies now emphasize the expansive complexity of today's intermedial links (and the viewer engagement that such intermediality is seen as begetting), other studies emphasize the internal complexity of the television texts in a new, lauded "golden age."7

Both of these moves (the turn to convergence and the aesthetic turn) are important, so I am certainly not suggesting that these aren't key areas of study. But in turning either out or in, these approaches (or, maybe, more accurately, how they've sometimes been characterized in discourses about television studies) can risk missing what is pivotal about their overlaps and interstices: that is, the way that TV exists precisely at the intersection of inside and outside, aesthetics and politics, communication and commerce, public and private, old and new, continuity and discontinuity, distinction and dispersal, mass and individual, and thus the way that TV necessarily impacts (and is impacted by) such social categories as gender, race, sexuality, and nationality that too are formed at exactly those intersections. In other words, I fear that questions of television's relation to those social formations, requiring a look not just outward nor just inward but at the place of their crossing, are no longer considered to be quite as pressing as they were during the time that I was building my archive. Instead, TV's complexity and significance is reified in itself, seen as produced purely technologically or textually, rather than in articulation with (and with implications for) those constructions of sociality and subjectivity that, from its very beginnings, feminist television studies had always tried to put at the forefront. In this way, television is removed from sociocultural dynamics. It is likewise removed from history through that emphasis on "currency" that mirrors TV's ownas if spectatorial dynamics, sexual and textual differences, and televisual communications and communities did not always involve complicated encounters, intricate webs of meaning, and a variety of investments (due not to technological or textual formations alone, but to their mutual coproduction with sociocultural formations). Indeed, it is just such intricacy, complexity, and variety that are materialized in my multifaceted archive.

\section{Video Clip 3}


This is an excerpt from the episode "A Chance of Showers" from Murphy Brown (CBS, May 11, 1992), which aired during the season in which the single Murphy was pregnant-a situation that disrupted (with sitcom hilarity) her personal life as a single woman and her professional life as a newscaster on the diegetic program FYI. In the episode, Murphy's co-worker Corky throws the reluctant Murphy a baby shower. Among the guests are the actual newswomen Katie Couric, Faith Daniels, Joan Lunden, Mary Alice Williams, and Paula Zahn, all playing themselves. It was reportedly this episode that prompted then Vice President Dan Quayle to make his remarks, in a speech on May 19, 1992, about Murphy Brown "mocking the importance of a father, by bearing a child alone, and calling it just another 'lifestyle choice."' Indeed, according to Quayle, Murphy Brown (particularly the lead character's decision to have a child as a single woman) promoted a "poverty of values" that, in his view, was partly to blame for the Los Angeles riots that broke out after the acquittal of the police officers charged with beating Rodney King (the ostensible subject of Quayle's speech). Quayle was mocked for conflating the real and the fictional in his remarks, though one might argue that, through its own strategies, the program encouraged precisely such conflations between the televisual and the real-albeit with the effect of encouraging a very different perspective on gender, sexuality, family, and community than the one Quayle voiced. Despite its historical importance, this episode has never been released on DVD, so (even with its bad technical quality) it is one of the valued gems of my archives.

So that old crazy archive-yes, it was somewhat haphazard. But it also made these hazards obvious, rather than effacing the risks either in claims for aesthetic prestige or in claims for a convergence populism that celebrates access to everything, but then, for that same reason, to nothing that is "just TV" (with, ironically, both the aesthetic and the technological celebrants thus converging in the dismissal of merely "ordinary" television). In its very uncoordinatedness, it revealed, I believe, the coordinates that place TV; its lack of design exposing the designations of TV's gendered, classed, raced, and nationalized address; its unsystematic illogic showing, symptomatically, something about TV's logic while still not just replicating that logic by accepting criteria of importance defined in terms of "sellability" or "critical acclaim." In that way, even as I passed it down to students, this archive formed, I think, less 
a canon to be professed than a collection (even if it was a professor's) to be played with, something less to be respected than to be rummaged through. Now, in the face of new ways of accessing television, my collection of old tapes is thought, literally, to be just junk for rummage. But I hope that, contrary to that assessment, I have indicated the value — pedagogical, intellectual, creative, and critical—of just such haphazard TV archives.

\section{Comment on this article}

\section{About the Author}

Lynne Joyrich is Professor of Modern Culture and Media at Brown University. She is the author of Re-viewing Reception: Television, Gender, and Postmodern Culture and of articles and chapters on film, television, feminist, queer, and cultural studies in such books as Private Screenings; Modernity and Mass Culture; Logics of Television; Inventing Film Studies; New Media, Old Media and Queer TV and such journals as Critical Inquiry, Cinema Journal, differences, Discourse, and others. She has been a member of the Camera Obscura editorial collective since 1996.

\section{Endnotes}

1 "U. of Md.'s Broadcast Archives Reflect Bygone Era," SmartBrief, June 12, 2014, http://www.smartbrief.com/06/12/14/u-mds-broadcastarchives-reflect-bygone-era\#.U88ZjKgYF4o (accessed July $22,2014)$. This short summary is referencing the longer article by John Kelly, "University of Maryland Archive Specializes in Collecting Material from History of Radio, TV," Washington Post, June 11, 2014, http://www.washingtonpost.com/local/university-of-marylandarchive-specializes-in-collecting-material-from-history-ofradio-tv/2014/06/11/d407ab46-f160-11e3-914c1fbd0614e2d4_story.html, (accessed July 22, 2014).

$\underline{2}$ I've elaborated these points in more detail across my work. See, for instance, Lynne Joyrich, "Queer Television Studies: Currents, Flows, and (Main)Streams," in the section "In Focus: Queer Approaches to Film, Television, and Digital Media," Cinema Journal 53.2 (Winter 2014), 133-39 doi:10.1353/cj.2014.0015; Joyrich, "Media Madness: 
Multiple Identity (Dis)Order in Mad Men," in Mad Men, Mad

World: Sex, Politics, Style, and the 1960s, eds. Lauren

Goodlad, Robert Rushing, and Lilya Kaganovsky (Durham:

Duke University Press, 2013), 213-37

doi:10.1215/9780822399063-015; Joyrich, "Epistemology of the Console," Queer TV: Theories, Histories, Politics, eds.

Glyn Davis and Gary Needham (New York: Routledge, 2009), 15-47.

$\underline{3}$ This, of course, is not to say that new technologies of distribution and access aren't important-simply that it's key to see what they efface in TV logics and viewerships as much as what they encourage.

$\underline{4}$ I discuss these issues more fully in Lynne Joyrich, "Tubular Vision: The Ins and Outs of Television Studies," in New Media, Old Media: A History and Theory Reader, second ed., eds. Wendy Hui Kyong Chun and Thomas Keenan (New York: Routledge, forthcoming).

$\underline{5}$ There is a great deal of work in this area, but some key texts that have helped to establish this field of study include Lynn Spigel and Jan Olsson, eds., Television After TV: Essays on a Medium in Transition (Durham: Duke University Press, 2004); Henry Jenkins, Convergence Culture: Where Old and New Media Collide (New York: NYU Press, 2006); Amanda D. Lotz, The Television Will Be Revolutionized (New York: NYU Press, 2007); and Sharon Marie Ross, Beyond the Box: Television and the Internet (Malden, MA: Blackwell, 2008).

$\underline{6}$ The most notable work in this vein is Jason Mittell, Complex Television: The Poetics of Contemporary Television Storytelling (New York: NYU Press, 2015). For discussions and debates about aesthetic judgment and television studies, see also Kim Akass and Janet McCabe, eds., Quality TV: Contemporary American Television and Beyond (London and New York: I.B. Tauris, 2007) and Stephen Peacock and Janet Jacobs, eds., Television Aesthetics and Style (London and New York: Bloomsbury, 2013). For an analysis of the issues involved in "legitimating" television, see Michael Z. Newman and Elana Levine, Legitimating Television: Media Convergence and Cultural Status (London and New York: Routledge, 2012). A crucial issue discussed in that book (and related to my own critique in this essay) is the gender hierarchy involved in such legitimation; for a book that also notes, yet arguably 
inadvertently enacts, such dynamics in its auteur approach to today's celebrated television, see Brett Martin, Difficult Men: Behind the Scenes of a Creative Revolution: From The Sopranos and The Wire to Mad Men and Breaking Bad (New York: Penguin Press, 2013). Finally, for a discussion of the significance of aestheticized "extras," like DVD packaging (not to mention DVDs' inclusions of authorial and aesthetic commentary), see Jonathan Gray, Show Sold Separately: Promos, Spoilers, and Other Media Paratexts (New York: NYU Press, 2010).

7 There is a great deal of discussion these days-both in academic and popular discourses-about a current "golden age" of TV. For one of the initiating discussions in the popular press, see Emily Nussbaum, "When TV Became Art: Goodbye Boob Tube, Hello Brain Food," New York Magazine, December 4, 2009, http://nymag.com/arts/all/aughts/62513/. More recent articles, TV reviews, blog posts, and so on that make claims about a new golden age in television are too numerous to cite. But, just as examples, see Todd Van Der Werff, "The Golden age of TV Is Dead; Long Live the Golden Age of TV," A.V. Club, September 20, 2013, http://www.avclub.com/article/the-golden-age-of-tv-is-deadlong-live-the-golden--103129; ; Adam Kirsch and Mohsin Hamid, "Are the New 'Golden Age' TV Shows the New Novels?" New York Times Sunday Book Review, February 25, 2014, http://www.nytimes.com/2014/03/02/books/review/are-thenew-golden-age-tv-shows-the-new-novels.html; and David Carr, "Barely Keeping Up in TV's New Golden Age," New York Times, March 9, 2014, http://www.nytimes.com/2014/03/10/business/media/fencedin-by-televisions-excess-of-excellence.html.

\section{Published by the Dartmouth College Library. Copyright (C) Trustees of Dartmouth College. CC BY-NC 4.0 http://journals.dartmouth.edu/joems/

